\title{
Reconfigurable of current-mode differentiator and integrator based-on current conveyor transconductance amplifiers
}

\author{
Soontorn Srisoontorn ${ }^{1}$, Angkana Charoenmee ${ }^{1}$, Suphaphorn Panikhom ${ }^{1}$, Thitiporn Janda ${ }^{2}$, \\ Suttipong Fungdetch ${ }^{2}$, Khunpan Patimaprakorn ${ }^{3}$, Adirek Jantakun ${ }^{1}$ \\ ${ }^{1}$ Department of Electronics and Telecommunication Engineering, Faculty of Engineering, Rajamangala University of Technology Isan, \\ Khon Kaen Campus, Khon Kaen, Thailand \\ ${ }^{2}$ Department of Electronics and Telecommunication Engineering, Faculty of Technical Education, Rajamangala University of \\ Technology Isan, Khon Kaen Campus, Khon Kaen, Thailand \\ ${ }^{3}$ Department of Electrical Engineering, Faculty of Engineering, Rajamangala University of Technology Isan, Khon Kaen Campus, \\ Khon Kaen, Thailand
}

\begin{tabular}{|c|c|}
\hline Article Info & ABSTRACT \\
\hline Article history: & The reconfigurable of the differentiator and integrator based on current \\
\hline Received Feb 14, 2021 & $\begin{array}{l}\text { conveyor transconductance amplifiers (CCTAs) have been presented in this } \\
\text { paper. The proposed configurations are provided with two CCTAs and }\end{array}$ \\
\hline Revised Jun 16, 2021 & grounded elements. The configurations can be operated in the differentiator \\
\hline Accepted Jun 29, 2021 & $\begin{array}{l}\text { and integrator by selecting external passive elements. The input and output } \\
\text { currents have low and high impedances, respectively; therefore, the }\end{array}$ \\
\hline Keywords: & $\begin{array}{l}\text { configurations can be cascaded without additional current buffer. The } \\
\text { proposed configurations can be electronically tuned by external direct }\end{array}$ \\
\hline CСТА & current (DC) bias currents, and it also has slight fluctuation with \\
\hline Current-mode & $\begin{array}{l}\text { temperature. An application of universal filter is demonstrated to confirm the } \\
\text { ability of the proposed configurations. The results of simulation with Pspice }\end{array}$ \\
\hline Differentiator & program are accordance with the theoretical analysis. \\
\hline Grounded element & \\
\hline
\end{tabular}

This is an open access article under the $\underline{C C B Y-S A}$ license.

Integrator

\section{Corresponding Author:}

Adirek Jantakun

Department of Electronics and Telecommunication Engineering, Faculty of Engineering

Rajamangala University of Technology Isan

Khon Kaen Campus, Khon Kaen, Thailand

Email: Adirek.ja@rmuti.ac.th

\section{INTRODUCTION}

Analog signal processing circuits such as sinusoidal oscillator [1]-[5], and second-order filter [6][10] have been numerously researched and published. Fundamentally, the background of these is synthesized or designed with the differentiator or integrator [11]-[40]. They are designed or synthesized with the highperformance active building block such as operational amplifier (OPAMP) [11], [12], [15], [36], current conveyor second generation (CCII) [16], [17], [33], current feedback amplifier (CFA) [13], [18]-[20], [23], [24], [27], [30]-[32], current controlled current feedback amplifier (CC-CFA) [21], current controlled current differencing buffered amplifier (CCCDBA) [22], operational transconductance amplifier (OTA) [26], [35], [39], current follower transconductance amplifier (CFTA) [28], and current conveyor transconductance amplifier (CCTA) [40]. The remark details of them can be explained as follows.

The differentiators and integrators in [11], [12], [15], [36] are configured with OPAMP; however, they have the uses of excessive external passive elements. The next circuits in [16], [17], [33], [34], [37] have higher bandwidth than some researches as [11], [12], [15], but their time constant has not been tuned by electronic method. Next, the CFA of [18], [19], [24], [27] implements the differentiator and integrator circuits by using a lot of external passive elements. The proposed circuits in [13], [20], [23], [25], [30], [32] 
are designed for electronic tuning by using a multiplier circuit, but two types of the different active elements have been used. The differentiators and integrators of [14], [21], [22], [28], [40] can be electronically tuned the time constant although they are still sensitive to the temperature. Furthermore, some proposed circuits in [11], [12], [15], [17]-[19], [22], [25], [30], [31], [37] use the floating capacitor that is not suitable for the integrated circuit fabrication. The configurations in [13], [14], [23], [28], [34], [40] are operated in the integrator while those in [15], [27] [31], [38], [39] are served to operated in the differentiator. The comparison of the differentiator and integrator circuits can be shown in Table 1.

This paper presents two configurations of the current-mode differentiator and integrator with temperature-insensitive. They have the same features and the uses of grounded passive elements which are the ideal for the fabrication in IC. Furthermore, the configurations can be electronically controlled by direct current (DC) bias currents of the current conveyor transconductance amplifier (CCTA). The input and output currents have low and high impedances, respectively, so they are appropriate for the configurations to be cascaded without additional current buffers. An application of the configurations for filter is demonstrated. The details of the proposed configurations can be explained in the following topics.

Table 1. The comparison of the differentiator and integrator and recent researches

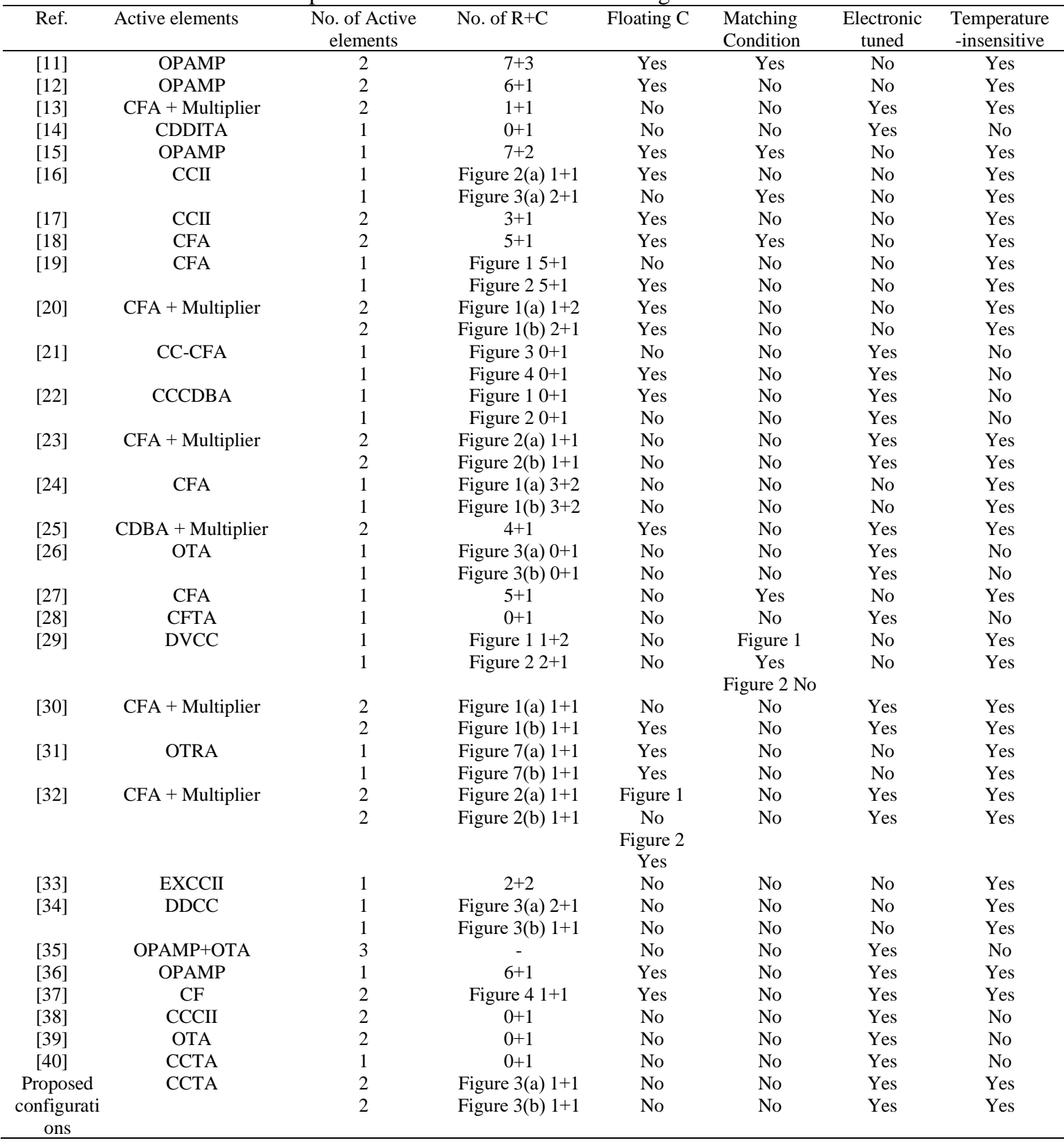




\section{RESEARCH METHOD}

The explanation of the research chronology, including the current conveyor transconductance amplifier (CCTA), proposed confiurations, computer simulation, and conclusion can be detailed as follows.

\subsection{The CCTA details}

The synthesis of analog circuit using active building block has constantly become interesting and understood [41]-[43]. CCTA is an active building block used for realization. Thus, this section describes the CCTA properties since the CCTA is the main active building block in our proposed circuit. The CCTA was researched and published by Prokop and Jesda [44]. It was versatile in analog signal processing and also extremely used in the current-mode and voltage-mode circuits. The ideal characteristic of the CCTA can be described by (1):

$$
\left[\begin{array}{l}
I_{y} \\
V_{x} \\
I_{z} \\
I_{o}
\end{array}\right]=\left[\begin{array}{cccc}
0 & 0 & 0 & 0 \\
0 & 1 & 0 & 0 \\
1 & 0 & 0 & 0 \\
0 & 0 & \pm g_{m} & 0
\end{array}\right]\left[\begin{array}{l}
I_{x} \\
V_{y} \\
V_{z} \\
V_{o}
\end{array}\right],
$$

where $\mathrm{g}_{\mathrm{m}}$ is the transconductance gain of the CCTA. The electrical symbol and equivalent circuit of the CCTA is presented in Figure 1 (a) and 1 (b), respectively. The BJT implementation of the CCTA is shown in Figure 2. The $g_{m}$ of CCTA is presented as in (2):

$$
g_{m}=\frac{I_{B}}{2 V_{T}},
$$

where $\mathrm{V}_{\mathrm{T}}$ is the thermal voltage and about $26 \mathrm{mV}$. It is evident that $\mathrm{I}_{\mathrm{B}}$ is the external DC bias current for adjusting $\mathrm{g}_{\mathrm{m}}$; this is called electronic tune.

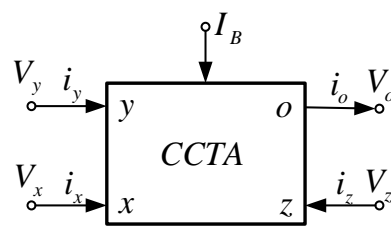

(a)

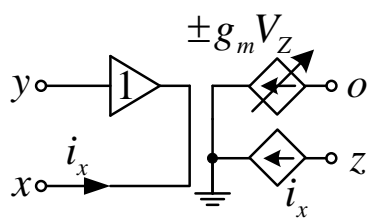

(b)

Figure 1. CCTA (a) electrical symbol, and (b) equivalent circuit

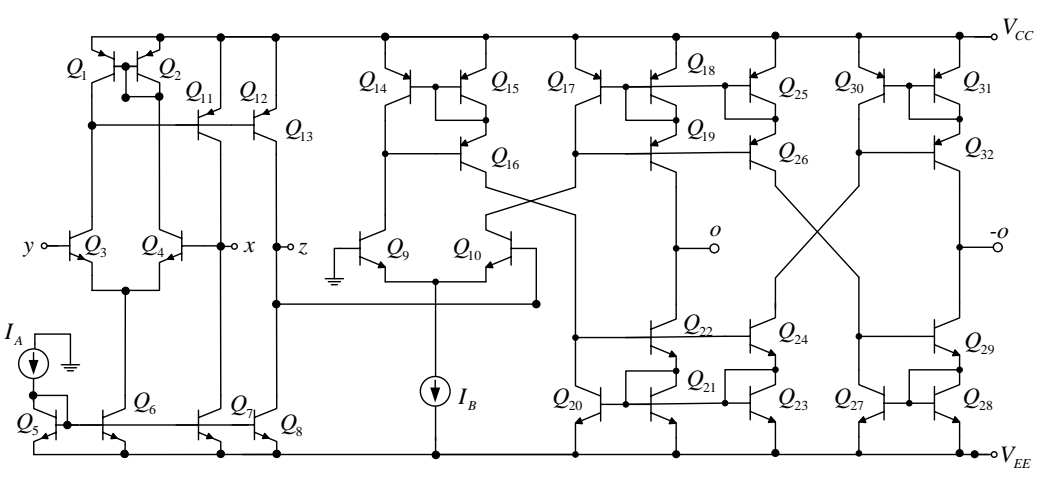

Figure 2. The internal construction of the CCTA

\subsection{The proposed configurations}

The proposed configurations based on CCTAs and grounded elements can be simply realized and illustrated in Figure 3. It is interesting that both configurations show the same efficiency. They are provided 
with two CCTAs and grounded elements which are suitable for the integrated circuit architecture [2]. Especially, the input and output impedances of the configurations are low and high, respectively, that is idealization for the current-mode configuration [9]. To realize the corresponding transfer functions of the proposed configurations in Figure 3, the ideal characteristic of CCTA can be used. They are found that the current transfer functions of the proposed configurations are the same as the (3).

$$
\frac{I_{\text {out }}(s)}{I_{\text {in }}(s)}=\frac{g_{m 1} z_{1}}{g_{m 2} z_{2}}
$$

To accomplish the current transfer functions, $g_{m 1}$ and $g_{m 2}$ in (3) can be substituted, the transfer function of the proposed configurations can be represented as (4).

$$
\frac{I_{\text {out }}(s)}{I_{\text {in }}(s)}=\frac{I_{B 1} Z_{1}}{I_{B 2} Z_{2}}
$$

From the (4), it is noticeable that the gain of proposed circuits can be electronically controlled/tuned with external DC bias currents $I_{B 1}$ and $I_{B 2}$ or both. Furthermore, the transfer function without terms of $\mathrm{V}_{\mathrm{T}}$ in our proposed circuits are free from the temperature of an environment.

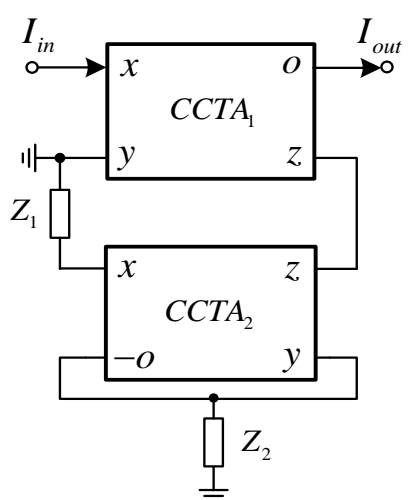

(a)

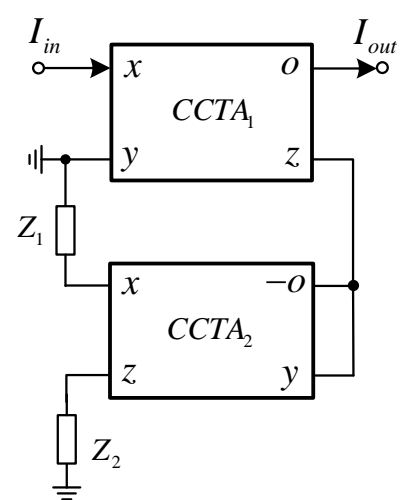

(b)

Figure 3. Proposed configurations

\subsection{The operation of differentiator}

The proposed configurations in Figure 3 can be operated to the differentiator by setting $Z_{1}=R_{1}$ and $Z_{2}=1 / C_{1 S}$. It is seen that the capacitor $C_{1}$ is connected to the ground at high-impedance port of CCTA, which is beneficial to elimination/compensation of the internal capacity of CCTA and parasitic capacity at circuit node. Furthermore, the grounded resistor $R_{1}$ is connected at low-impedance port, which is the suitable support of internal resistance of the CCTA. The current transfer function of (4) then turns into the following (5).

$$
\frac{I_{\text {out }}(s)}{I_{\text {in }}(s)}=\frac{I_{B 1}}{I_{B 2}} R_{1} C_{1} s=\tau s
$$

Where $\tau$ is time constant and it will be equal to:

$$
\tau=\frac{I_{B 1}}{I_{B 2}} R_{1} C_{1}
$$

The magnitude of current transfer function is proportionally dependent on the frequency that is (7).

$$
\left|\frac{I_{\text {out }}(j \omega)}{I_{\text {in }}(j \omega)}\right|=\frac{I_{B 1}}{I_{B 2}} R_{1} C_{1} \omega .
$$

Moreover, the magnitude can be tuned by external DC bias currents $I_{B 1}$ and $I_{B 2}$ or both. The phase response is exhibited in (8). 


$$
\frac{I_{\text {out }}(j \omega)}{I_{\text {in }}(j \omega)}=\frac{I_{B 1}}{I_{B 2}} R_{1} C_{1} \omega e^{j 90}
$$

The phase response of the output signal $I_{\text {out }}$ and input signal $I_{\text {in }}$ is $90^{\circ}$ shift for all frequencies.

\subsection{The operation of integrator}

The operation of integrator can be operated by configuring $Z_{1}=1 / C_{1 S}$ and $Z_{2}=R_{1}$ as Figure 3 . Then the current transfer function is modified as (9).

$$
\frac{I_{\text {out }}(s)}{I_{\text {in }}(s)}=\frac{I_{B 1}}{I_{B 2} R_{1} C_{1} s}=\frac{1}{\tau s}
$$

Where $\tau$ is defined as (10).

$$
\tau=\frac{I_{B 2} R_{1} C_{1}}{I_{B 1}}
$$

From (9), the magnitude can be analyzed by (11).

$$
\left|\frac{I_{\text {out }}(j \omega)}{I_{\text {in }}(j \omega)}\right|=\frac{I_{B 1}}{I_{B 2} R_{1} C_{1} \omega} .
$$

The magnitude can be easily operated by adjusting both of the external bias currents $I_{B 1}$ and $I_{B 2}$. For realization of the phase response, it can be depicted as (12).

$$
\frac{I_{\text {out }}(j \omega)}{I_{\text {in }}(j \omega)}=\frac{I_{B 1}}{I_{B 2} R_{1} C_{1} \omega} e^{-j 90^{\circ}}
$$

It is sure that the phase of output signal $I_{\text {out }}$ is lagging of input signal $I_{\text {in }}$ which is $90^{\circ}$.

\subsection{Non-ideal analysis}

For non-ideal analysis, we examine the transfer errors of CCTA due to the mismatch of the internal construction and parasitic elements of the CCTA. The characteristic of the CCTA with the tracking errors can be shown in (13).

$$
\left[\begin{array}{l}
I_{y} \\
V_{x} \\
I_{z} \\
I_{o}
\end{array}\right]=\left[\begin{array}{cccc}
0 & 0 & 0 & 0 \\
0 & \gamma & 0 & 0 \\
\alpha & 0 & 0 & 0 \\
0 & 0 & \pm \beta g_{m} & 0
\end{array}\right]\left[\begin{array}{l}
I_{x} \\
V_{y} \\
V_{z} \\
V_{o}
\end{array}\right]
$$

Where $\gamma$ is the voltage transfer error gain between $\mathrm{x}$ port and $\mathrm{y}$ port, $\alpha$ is the current transfer error gain between $\mathrm{x}$ port and $\mathrm{z}$ port, and $\beta$ is the transconductance error between $\mathrm{z}$ port to o port. These errors are deviated from the ideal unity that are called tracking errors. The current transfer function of the proposed configurations can be re-analyzed as in (14):

$$
\frac{I_{\text {out }}(s)}{I_{\text {in }}(s)}=\frac{g_{m 1} \beta_{1} \alpha_{1} Z_{1}}{g_{m 2} \beta_{2} \alpha_{2} \gamma_{2} Z_{2}} .
$$

However, these errors can be easily compensated/eliminated by slightly adjusting the DC bias currents of CCTA.

\subsection{The sensitivity analysis}

The sensitivities of active and passive elements must be analyzed since the performances of proposed configurations are deviated by the tolerances of the elements. The sensitivities of proposed differentiator are calculated as in (15). 


$$
S_{I_{B 1}}^{\tau}=S_{R_{1}}^{\tau}=S_{C_{1}}^{\tau}=1, S_{I_{B 2}}^{\tau}=-1, S_{V_{T}}^{\tau}=0
$$

Then the sensitivities of integrator can be declared by (16).

$$
S_{I_{B 1}}^{\tau}=-1, S_{I_{B 2}}^{\tau}=S_{R_{1}}^{\tau}=S_{C_{1}}^{\tau}=1, S_{V_{T}}^{\tau}=0
$$

It can be seen that the sensitivities of active and passive elements are low, which are equal unity in magnitude. In addition, the sensitivities of temperature are equal to zero, which are the proposed configuration insensitivities of temperature.

\subsection{An application for filters}

An application for filters is designed by cascading differentiators as the topology shown in Figure 4. The time constants are defined as $\tau_{1}=\frac{I_{B 1}}{I_{B 2}} R_{1} C_{1}$ and $\tau_{2}=\frac{I_{B 3}}{4} R_{2} C_{2}$. The output responses are composed of low-pass, band-pass, and high-pass. The transfer function of them can be depicted in (17)-(19).

$$
\begin{aligned}
& \frac{I_{L P}(s)}{I_{i n}(s)}=\frac{\frac{I_{B 2} I_{B 4}}{I_{B 1} I_{B 3} R_{1} R_{2} C_{1} C_{2}}}{s^{2}+\frac{I_{B 4}}{I_{B 3} R_{2} C_{2}} s+\frac{I_{B 2} I_{B 4}}{I_{B 1} I_{B 3} R_{1} R_{2} C_{1} C_{2}}} \\
& \frac{I_{B P}(s)}{I_{i n}(s)}=\frac{\frac{I_{B 4}}{I_{B 3} R_{2} C_{2}} s}{s^{2}+\frac{I_{B 4}}{I_{B 3} R_{2} C_{2}} s+\frac{I_{B 2} I_{B 4}}{I_{B 1} I_{B 3} R_{1} R_{2} C_{1} C_{2}}}
\end{aligned}
$$

and

$$
\frac{I_{H P}(s)}{I_{\text {in }}(s)}=\frac{s^{2}}{s^{2}+\frac{I_{B 4}}{I_{B 3} R_{2} C_{2}} s+\frac{I_{B 2} I_{B 4}}{I_{B 1} I_{B 3} R_{1} R_{2} C_{1} C_{2}}} .
$$

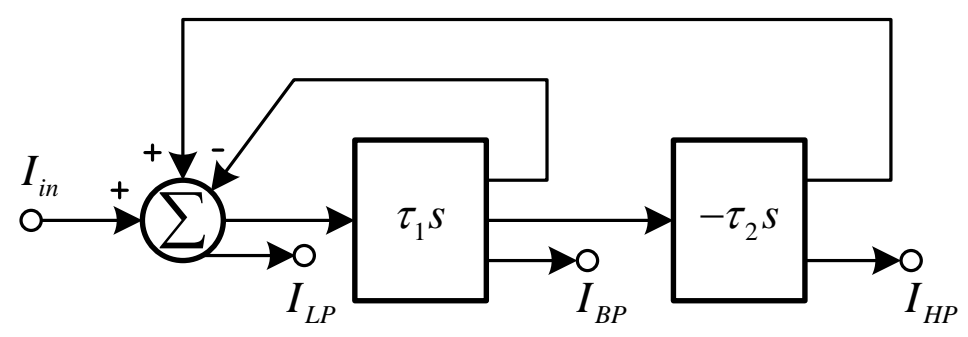

Figure 4. Topology of filter

The pole frequency $\left(\omega_{p}\right)$ and the quality factor $\left(Q_{P}\right)$ can be expressed as:

$$
\omega_{p}=\sqrt{\frac{I_{B 2} I_{B 4}}{I_{B 1} I_{B 3} R_{1} R_{2} C_{1} C_{2}}}
$$

and

$$
\mathcal{Q}_{P p}=\sqrt{\frac{I_{B 2} I_{B 3} R_{2} C_{2}}{I_{B 1} I_{B 4} R_{1} C_{1}}}
$$


The pole frequency and the quality factor are electronically tunable by adjusting the bias currents $I_{B 1}, I_{B 2}, I_{B 3}$ and $I_{B 4}$. In addition, the pole frequency can be freely tuned without affecting the quality of factor by simultaneously adjusting $I_{B 2}=I_{B 4}=I_{F}$.

\section{COMPUTER SIMULATION AND DISCUSSION}

The theoretical analysis will be confirmed by using the computer simulation. The Pspice program and the internal construction of the CCTA in Figure 2 are used for the simulation. The positive-negativepositive (PNP) and negative-positive-negative (NPN) transistors uses the parameters of the PR200N and NR200N bipolar transistors of ALA400 transistor array. The proposed configuration in Figure 3(a) is chosen as an example for confirmation of theoretical analysis. The active elements are bias with $\pm 1.5 \mathrm{~V}$ supply voltages and DC bias currents are $I_{A}=I_{B 1}=I_{B 2}=100 \mu \mathrm{A}$.

The proposed configuration was demonstrated for the differentiator by setting $Z_{1}=R_{1}=2.4 \mathrm{k} \Omega$ and $Z_{2}=C_{1}=0.5 \mathrm{nF}$. The first result is shown in Figure 5; it is the gain and phase response of the proposed differentiator against frequencies. It is found that the simulation result agrees with the theory. The gain responses can be demonstrated with adjusting the DC bias current of CCTA, when they are defined as $I_{B 2}=100 \mu A$ and varied as $I_{B 1}=50 \mu A, 100 \mu A, 200 \mu A$ and $400 \mu A$, respectively. It is evident that the theoretical and simulation results of gain responses in Figure 6 are very compatible. The confirmation of our proposed differentiator for the temperature-insensitive is verified by swepting temperature of $0,25,75$ and 100 degree Celsius. The simulation result in Figure 7 is very satisfying because the curves of gain and phase responses of our proposed differentiator are slightly dependent on temperature.

The time domain responses can be investigated by feeding a sinusoidal signal of $130.6 \mathrm{kHz}$ frequency with $80 \mu A p-p$ amplitude into the input of proposed circuit. When the proposed circuit is kept constant, then the external passive elements and the bias of active elements as above are mentioned. The current input $\left(I_{\text {in }}\right)$ and output $\left(I_{\text {out }}\right)$ waveforms are displayed in Figure 8 . The obtained results show that the phase shift between $\left(I_{\text {out }}\right)$ and $\left(I_{\text {in }}\right)$ is about $90^{\circ}$ as the Lissajous shown in Figure 9.

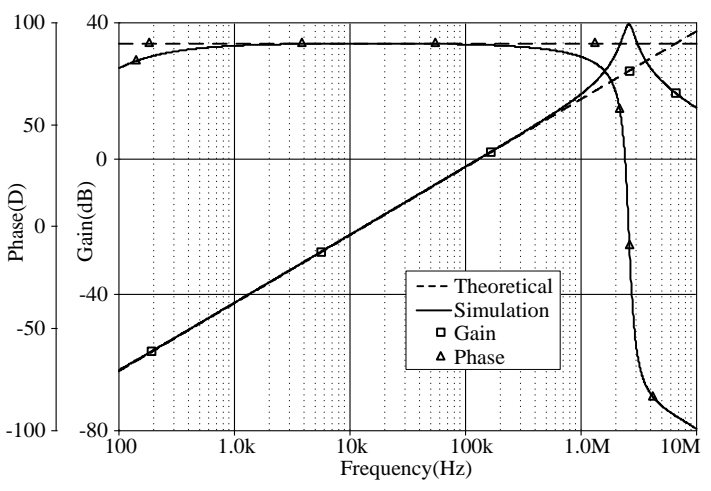

Figure 5. Gain and phase response

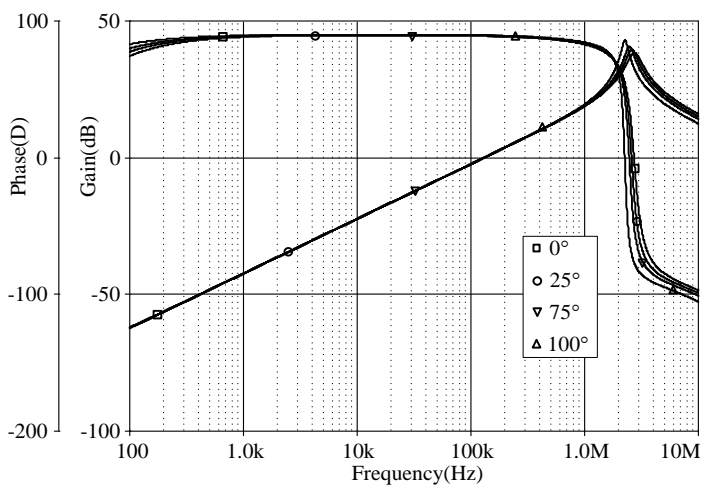

Figure 7. Gain and phase response due to difference temperatures

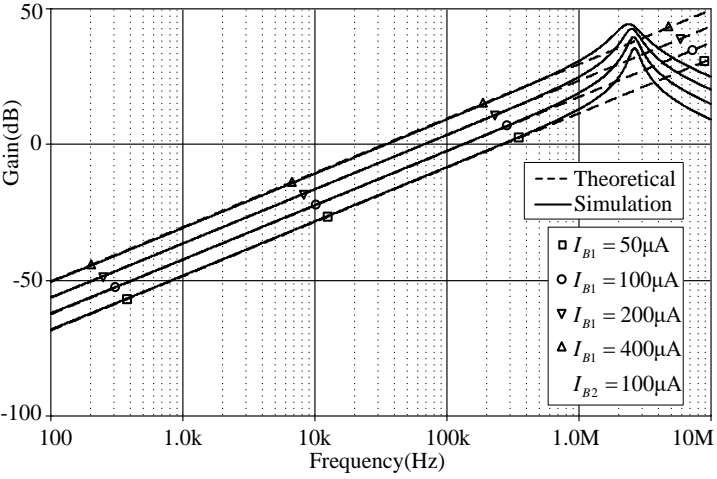

Figure 6. Adjustment of gain response with $\mathrm{I}_{\mathrm{B} 1}$

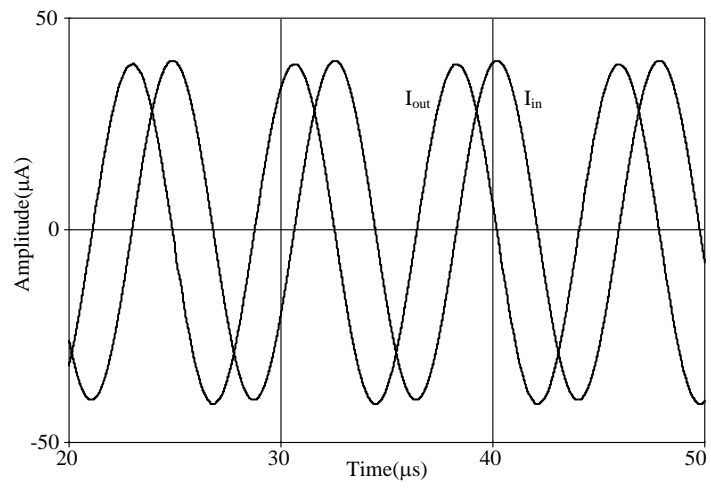

Figure 8 . The time domain response of our proposed circuit 
The adjustment of the current gain of our proposed circuit can be demonstrated with tuning the DC bias current, $I_{B 1}$, which are $I_{B 1}=50 \mu A, 100 \mu A$, and $150 \mu A$, respectively. The simulation result is shown in Figure 10 and also the current gain is given as 0.5, 1.0 and 1.5, respectively. Figure 11 depicts the temperature effect of the proposed differentiator when the temperature is varied as $0,25,50,75$ and 100 degree Celsius. It can be seen that the current output waveforms are constant by different temperature, which is in accordance with theoretical analysis in (4).

One of the differentiator properties is the transformation of the triangle wave to square wave. In this case, we feed the signal of the triangular wave with $200 \mathrm{kHz}$ frequency and $200 \mu \mathrm{A}$ into the input of proposed differentiator. The results can be shown in Figure 12 which are the input and output waveforms of proposed circuit. The temperature is varied as $0,25,75$ and 100 degree Celsius as the results of simulations shown in Figure 13. It is found that the output waveforms slightly affect the temperature.

The simulation of universal filter is set as $R_{1}=R_{2}=2.4 \mathrm{k} \Omega$ and $C_{1}=C_{2}=0.5 \mathrm{nF}$. The bias currents are configured with $I_{B 2}=I_{B 4}=I_{f}=I_{B 4}=100 \mu \mathrm{A}$. The gain responses of filters are plotted in Figure 14. There are low-pass, band-pass, and high-pass responses. The pole frequency and the quality factor are about $127.05 \mathrm{kHz}$ and 1, respectively. The confirmation of temperature insensitive of filters can be shown by varying the temperature as 0, 255075 and 100 degree Celsius. It can be clearly seen that the simulation results in Figure 15 are slightly dependent on temperature. The tuning of the pole frequency can be simulated in Figure 16 by tuning the bias currents as $I_{B 2}=I_{B 4}=I_{f}=50 \mu A, 100 \mu A$ and $200 \mu \mathrm{A}$, respectively. The pole frequencies are varied to $63.97 \mathrm{kHz}, 127.05 \mathrm{kHz}$ and $251.18 \mathrm{kHz}$, respectively. Therefore, the configurations are ideally offered for using in communication systems and other applications.

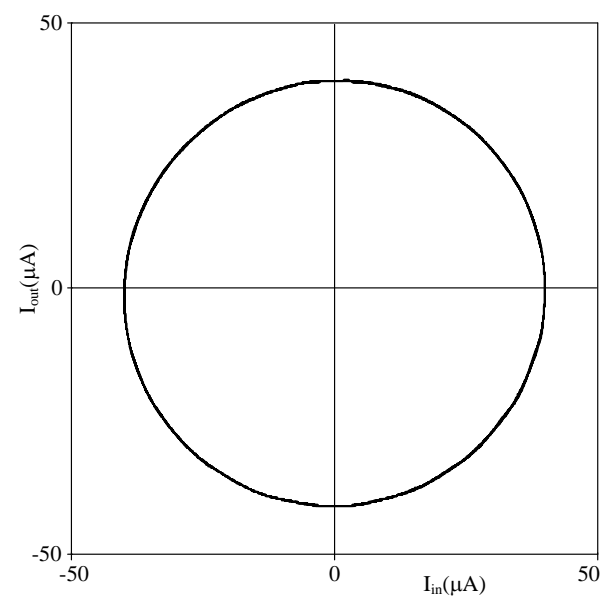

Figure 9. Lissajous figure of input and output waveforms

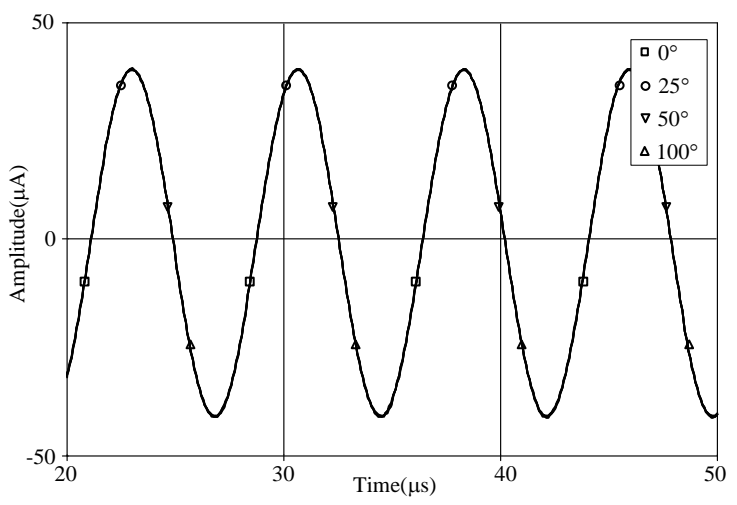

Figure 11. Output waveforms with different temperatures

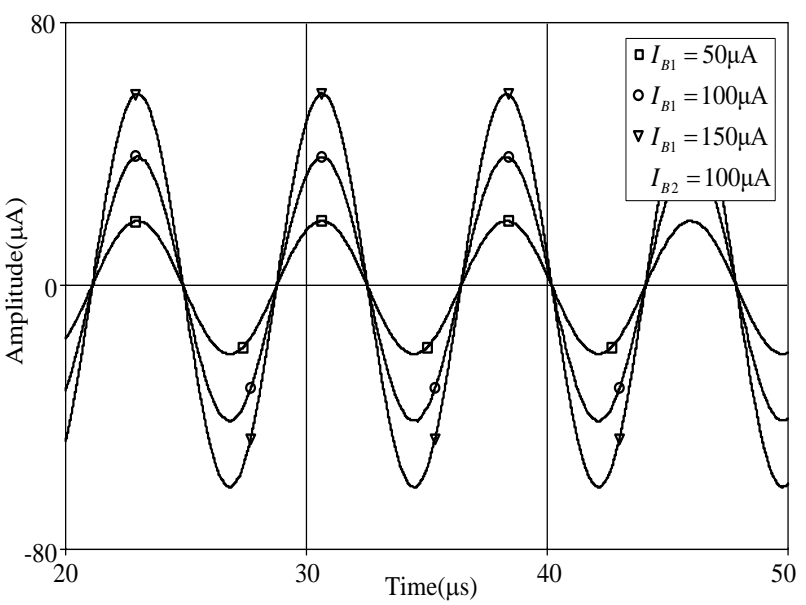

Figure 10. Amplitude of output signal with $I_{B 1}$ variations

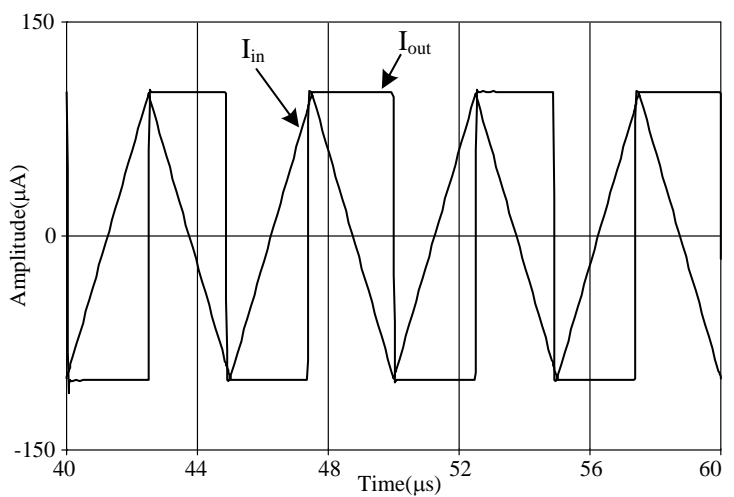

Figure 12. Input and output waveforms 


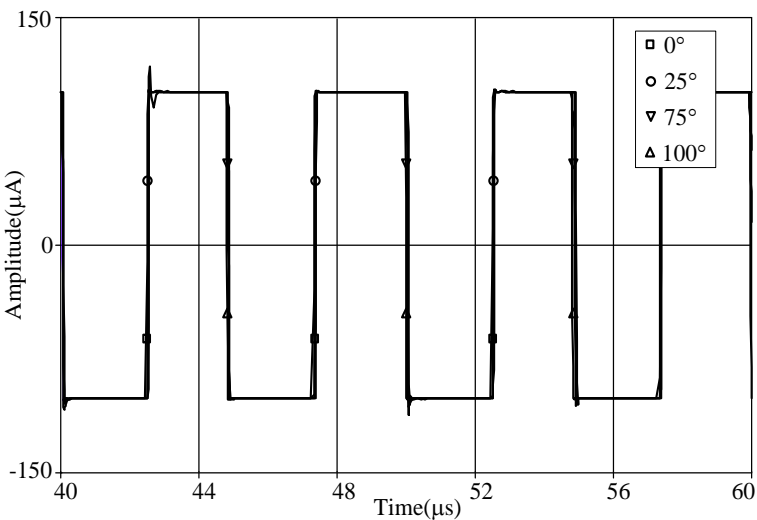

Figure 13. Output waveforms due to different temperatures

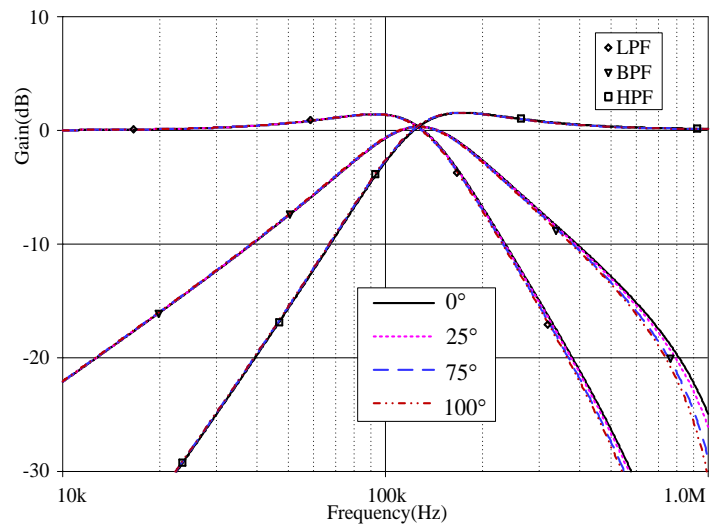

Figure 15. Gain responses of filters due to difference of the temperatures

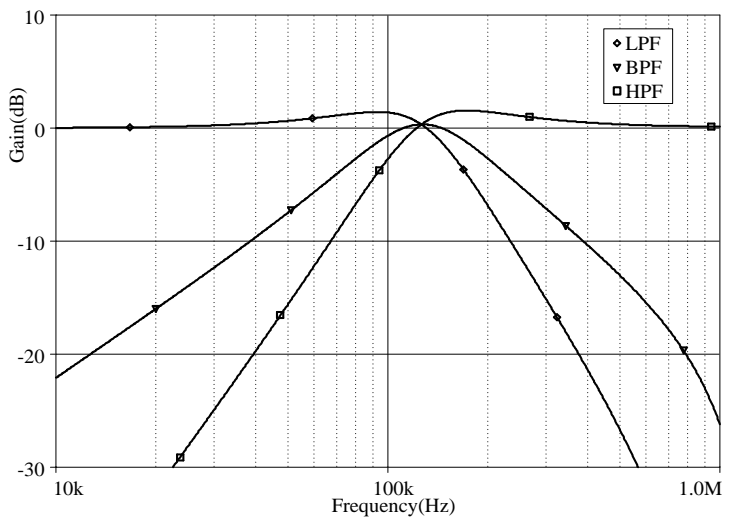

Figure 14. Gain responses of filters

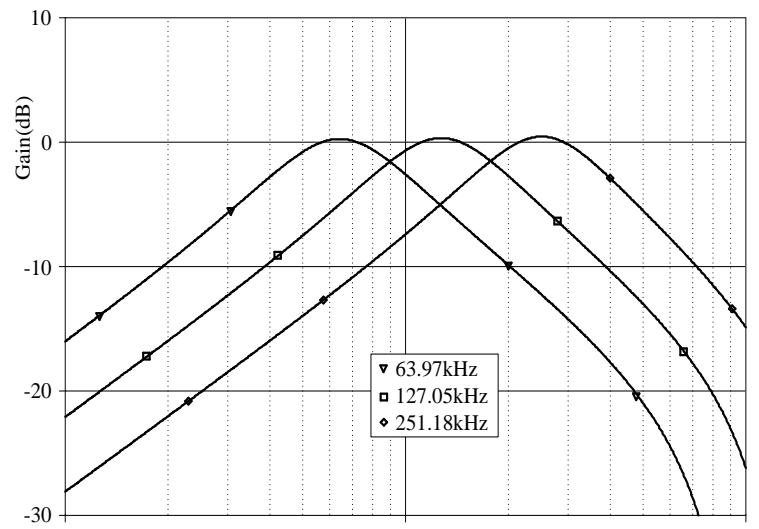

Figure 16. Gain responses of band-pass due to difference of the pole frequency

\section{CONCLUSION}

The two configurations of differentiator and integrator were presented. They are similarly configured and featured. The proposed configurations are configured of 2 CCTAs and grounded elements. The input and output impedance of configurations are low and high, respectively. They are operated to differentiator and integrator by the selection of external passive elements. Furthermore, the proposed configuration can be electronically tuned that is suitable for using in communication or control systems. Moreover, they are not sensitive to the temperature. An application of the configuration for filter shows the usability. The performances of our proposed configurations are verified by Pspice program. The simulation results are in line with the theoretical analysis.

\section{ACKNOWLEDGEMENTS}

This work was supported by the Faculty of Engineering, under Grant ENG28/62, Rajamangala University of Technology Isan, Khon Kaen Campus, Khon Kaen, Thailand.

\section{REFERENCES}

[1] W. Jaikla, S. Adhan, P. Suwanjan and M. Kumngern, "Current/voltage controlled quadrature sinusoidal oscillator for phase sensitive detection using commercially available IC," Sensors, vol. 20, no. 5, 2020, Art. no. 1319, doi: 10.3390/s20051319.

[2] F. Yucel and E. Yuce, "Supplementary CCII based second-order universal filter and quadrature oscillators," AEU-International Journal of Electronics and Communications, vol. 118, 2020, Art. no. 153138, doi: 10.1016/j.aeue.2020.153138.

[3] S. Rungsa, "Single commercially available IC: LT1228 based sinusoidal oscillator," Przegląd Elektrotechniczny, vol. 1, no. 4, pp. 220-224, 2019, doi: 10.15199/48.2019.04.41. 
[4] R. Sotner, Z. Hrubos, N. Herencsar, J. Jerabek, T. Dostal and K. Vrba, "Precise electronically adjustable oscillator suitable for quadrature signal generation employing active elements with current and voltage gain control," Circuits Systems and Signal Processing, vol. 33, no. 1, pp. 1-35, 2014, doi: 10.1007/s00034-013-9623-2.

[5] P. Supavarasuwat, M. Kumngern, S. Sangyaem, W. Jaikla, F. Khateb, "Cascadable independently and electronically tunable voltage-mode universal filter with grounded passive components," AEU-International Journal of Electronics and Communications, vol. 84, pp. 290-299, 2018, doi: 10.1016/j.aeue.2017.12.002.

[6] W. Jaikla, F. Khateb, T. Kulej and K. Pitaksuttayaprot, "Universal filter based on compact CMOS structure of VDDDA," Sensors, vol. 21, no. 5, 2021, Art. no. 1683, doi: 10.3390/s21051683.

[7] P. Kumar and N. Pandey, "Realization of resistorless and electronically tunable inverse filters using VDTA," Journal of Circuits, Systems, and Computers, vol. 28, no. 9, pp. 950143-1-950143-20, 2019, doi: 10.1142/S0218126619501433.

[8] D. Prasad, D. R. Bhaskar, and M. Srivastava, "New single VDCC-based explicit current-mode SRCO employing all grounded passive components," Electronics, vol. 18, no. 2, pp. 81-88, 2014, doi: 10.7251/ELS1418081P

[9] W. Jaikla et al., "Synthesis of biquad Filters using Two VD-DIBAs with independent control of quality factor and natural frequency," AEU-International Journal of Electronics and Communications, vol. 132, 2021, Art. no. 153601, doi: 10.1016/j.aeue.2020.153601.

[10] A. Jantakun, "The configuration of current-mode single-input multi-output, multi-input single-output biquad filter and quadrature oscillator based-on BiCMOS CCCTAs," Przeglad Elektrotechniczny, vol. 1, no. 7, pp. 104-109, 2017, doi: 10.15199/48.2017.07.23.

[11] S. Venkateswaran and R. K. Radhakrishna, "Multifunction active RC circuit with grounded capacitors," Electronics Letters, vol. 7, no. 24, pp. 708-710, 1971, doi: 10.1049/el:19710486.

[12] D. H. Horrocks, "A non-inverting differentiator using a single operational amplifier," International Journal of Electronics, vol. 37, no. 3, pp. 433-434, 1974, doi: 10.1080/00207217408900541.

[13] U. C. Sarker, S. K. Sanyal, and R. Nandi, "A high-quality dual-input differentiator," IEEE Transactions on Instrumentation and Measurement, vol. 39, no. 5, pp. 726-729, 1990, doi: 10.1109/19.58615.

[14] K. Panwar, D. Prasad, M. Srivastava, and Z. Haseeb, "New current mode lossy integrator employing CDDITA," Circuits and Systems, vol. 9, no. 8, pp. 117-123, 2018, doi: 10.4236/cs.2018.98012.

[15] M. A. Al-Alaoui, "A novel differential differentiator," IEEE Transactions on Instrumentation and Measurement, vol. 40, no. 5, pp. 826-830, 1991, doi: 10.1109/19.106305.

[16] D. Patranabis and D. K. Ghosh, "Integrators and differentiators with current conveyors," IEEE Transactions on Circuits and Systems, vol. 31, no. 6, pp. 567-569, 1984, doi: 10.1109/TCS.1984.1085535.

[17] S. I. Liu and Y. S. Hwang, "Dual-input differentiators and integrators with tunable time constants using current conveyors," IEEE Transactions on Instrumentation and Measurement, vol. 43, no. 4, pp. 650-654, 1994, doi: 10.1109/19.310164

[18] J. L. Lee and S. I. Liu, "Dual-input RC integrator and differentiator with tuneable time constants using current feedback amplifiers," Electronics Letters, vol. 35, no. 22, pp. 1910-1911, 1999, doi: 10.1049/el:19991316.

[19] J. L. Lee and S. I. Liu, "Integrator and differentiator with time constant multiplication using current feedback amplifier," Electronics Letters, vol. 37, no. 6, pp. 331-333, 2001, doi: 10.1049/el:20010252.

[20] R. K. Nagaria, A. Goswami, P. Venkateswaran, S. K. Sanyal, and R. Nandi, "Voltage controlled integrators/differentiators using current feedback amplifier," International Symposium on Signals, Circuits and Systems, 2003, vol. 2, pp. 573-576, 2003, doi: 10.1109/SCS.2003.1227117.

[21] J. Kumbun, P. Silapan, M. Siripruchyanun, and P. Prommee, "A current-mode quadrature oscillator based on CC-CFAs," 2009 6th International Conference on Electrical Engineering/Electronics, Computer, Telecommunications and Information Technology, 2009, pp. 542-545, doi: 10.1109/ECTICON.2009.5137066.

[22] V. Ramola, S. Mishra, R. K. Singh, and D. S. Chauhan, "Design of CCCCDBA based voltage mode differentiator and integrator," Proceedings of the International Conference on Advances in Electronics, Electrical and Computer Science Engineering (EEC2012), 2012, pp. 109-112.

[23] P. Venkateswaran, R. Nandi, and S. Das, "Voltage controlled integrator and linear quadrature VCO using MMCC," Buletin Teknik Elektro dan Informatika (BEEI), vol. 2, no. 2, pp. 111-116, 2013, doi: 10.12928/eei.v2i2.213.

[24] I. P. Singh and K. Singh, "A review on single CFA based multifunction network for analog signal processing," International Journal of Electronic and Electrical Engineering, vol. 4, no. 1, pp. 33-42, 2011.

[25] R. Nandi, K. Mousiki, and S. Das, "Electronically tunable dual-input integrator employing a single CDBA and a multiplier: voltage controlled quadrature oscillator," Active and Passive Electronic Component, vol. 2009, pp. 1-5, 2009, Art. no. 835789, doi: $10.115 / 2009 / 835789$

[26] M. Somdunyakanok et al., "Current-mode quadrature sinusoidal oscillator based on integrator and differentiator," The Journal of KMUTNB, vol. 18 , no. 3, pp. 41-48, 2008.

[27] J. W. Horng and G. T. Huang, "A grounded capacitor differentiator using current feedback amplifier," Circuits and Systems, vol. 4 , no. 2, pp. 233-236, 2013, doi: $10.4236 /$ cs.2013.42031

[28] W. Jaikla and A. Thitinaruemit, "A synthesis and design of electronically tunable current-mode integrator and its applications," World Academy of Science, Engineering and Technology, vol. 69, pp. 1715-1718, 2012.

[29] S. Minaei, "Dual-input current-mode integrator and differentiator using single dvcc and grounded passive elements," Proceedings of the 12th IEEE Mediterranean Electrotechnical Conference (IEEE Cat. No.04CH37521, 2004), pp. 123-126, doi: 10.1109/MELCON.2004.1346788

[30] R. K. Nagaria, "On the new design of CFA based voltage controlled integrator/differentiator suitable for analog signal processing," WSEAS Transaction on Electronics, vol. 5, no. 6, pp. 232-237, 2008.

[31] N. Pandey, R. Pandey, R. Anurag, R. Vijay, "A class of differentiator-based multifunction biquad filters using OTRAs," Advances in Electrical and Electronic Engineering, vol. 18, no. 1, pp. 31-40, 2020, doi: 10.15598/aeee.v18i1.3363

[32] P. Venkateswaran, R. Nandi, S. Das, "new integrators and differentiators using a MMCC," Circuits and Systems, vol. 3, no. 3, pp. 288-294, 2012, doi: 10.4236/cs.2012.33040

[33] S. Kapoulea, C. Psychalinos, and A. S. Elwakil, "Single active element implementation of fractional-order differentiators and integrators," AEU - International Journal of Electronics and Communications, vol. 97, pp. 6-15, 2018, doi: 10.1016/j.aeue.2018.09.046.

[34] E. Yuce, "Novel instrumentation amplifier and integrator circuits using single DDCC and only grounded passive elements," Indian Journal of Pure and Applied Physics, vol. 52, no. 11, pp. 767-775, 2014.

[35] S. Minaei, G. Topcu, and O. Çiçekoğlu, "Active only integrator and differentiator with tunable time constants," International Journal of Electronics, vol. 90, no. 9, pp. 581-588, 2003, doi: 10.1080/0014184032000159354 
[36] D. Patranabis and A. N. Paul, "Generating a family of grounded capacitor ideal integrators and differentiators," International Journal of Circuit Theory and Applications, vol. 9, no 2, pp. 245-250, 1981, doi: 10.1002/cta.4490090213.

[37] H. Alzaher, "Current follower based reconfigurable integrator/differentiator circuits with passive and active components," Microelectronics Journal, vol. 46 no. 2, pp. 135-142, 2015, doi: 10.1016/j.mejo.2014.12.001.

[38] P. Prommee, M. Somdunyakanok, and K. Angkeaw, "CCCII-based multiphase sinusoidal oscillator employing high-pass sections," 2009 6th International Conference on Electrical Engineering/Electronics, Computer, Telecommunications and Information Technology, vol. 1, 2009, pp. 530-533, doi: 10.1109/ECTICON.2009.5137063.

[39] N. Wongprommoon, A. Tiamsuphat, and P. Prommee, "Low-complexity chebyshev high-pass filter based on OTA-C," 2020 43rd International Conference on Telecommunications and Signal Processing (TSP), Milan, Italy, 2020, pp. 373-376, doi: 10.1109/TSP49548.2020.9163437.

[40] T. Thosdeekoraphat, S. Summart, C. Saetiaw, S. Santalunai, and C. Thongsopa, "CCTAs based current-mode quadrature oscillator with high output impedances," International Journal of Electronics and Electrical Engineering, vol. 1, no. 1, pp. 52-56, 2013, doi: 10.12720/ijeee.1.1.52-56.

[41] W. Jaikla, R. Sotner, and F. Khateb, "Design and analysis of floating inductance simulators using vdddas and their applications," AEU-International Journal of Electronics and Communications, vol. 112, 2019, Art. no. 152937, doi: 10.1016/j.aeue.2019.152937.

[42] W. Jaikla et al., "0.5 V fully differential universal filter based on multiple input OTAs," IEEE Access, vol. 8, pp. 187832-187839, 2020, doi: 10.1109/ACCESS.2020.3030239.

[43] P. Huaihongthong et al., "Single-input multiple-output voltage-mode shadow filter based on VDDDAs," AEU-International Journal of Electronics and Communications, vol. 103, pp. 13-23, 2019, doi: 10.1016/j.aeue.2019.02.013.

[44] R. Prokop and V. Musil, "New modern circuit block CCTA and some of its applications," The Fourteenth International Scientific and Applied Science Conference - Electronics ET'2005, 2005, pp. 93-98. 